Academic Platform Journal of Engineering and Science

journal homepage: http://apjes.com/

\title{
AISI 316 Ti Paslanmaz Çeliklerin İşleme Parametrelerinin Optimizasyonu
}

\author{
*Gültekin Basmac1 \\ Mehmet Akif Ersoy Üniversitesi Mühendislik-Mimarlık Fakültesi Makine Müh. Bölümü, Burdur \\ gbasmaci@mehmetakif.edu.tr
}

Araştırma Makalesi

Geliş Tarihi: 10.05 .2018

Kabul Tarihi: 27.07.2018

$\ddot{O} z$

Bu çalışmada; mekanik özelliklerinin yüksek, korozyon direnci iyi olması ve düşük 1sıl iletkenlikleri ile imalat sektöründe önemli bir kullanım sahasına AISI 316Ti paslanmaz çelikler deney malzemesi olarak kullanılmıştır. Tornalama da ilerleme oranının, talaş derinliğinin ve soğutma sisteminin yüzey pürüzlülüğüne ve kesme kuvvetlerine etkisi araştırıldı. Deneylerde $0.1,0.2$ ve 0.3 $\mathrm{mm} / \mathrm{dev}$ ilerleme oranı, $0.5,1$ ve $1.5 \mathrm{~mm}$ talaş derinliği ve kuru, MQL ve $\mathrm{CO}_{2}$ işleme parametreleri değişken olarak kullanılmıştır. Kesme hızı sabit tutulmuştur. Tornalama işleminin deneysel tasarımı için Taguchi tekniği kullanıldı. Bu teknik sayesinde az sayıda yapılan deneyle optimum değerler elde edilmiştir. Ayrıca en iyi parametre seviyelerinin belirlenmesi için Gri İlişki analizi metodu kullanıldı. En ideal GRA değeri 0,994 olarak 1'nolu deneyden elde edilmiştir. Buna göre en düşük yüzey pürüzlüğü ve kesme kuvveti için talaş derinliği ve ilerleme değerlerinin minimum tutulması gerekmektedir.

Anahtar Kelimeler: Gri İlişki Analizi, Optimizasyon, AISI 316Ti

\section{Optimization of Processing Parameters of AISI 316 Ti Stainless Steels}

\author{
*Gültekin Basmac1 \\ Department of Mechanical Engineering, Faculty of Engineering and Architecture, Mehmet Akif Ersoy University, Burdur, \\ TURKEY \\ gbasmaci@mehmetakif.edu.tr
}

\begin{abstract}
In this study; AISI 316Ti stainless steels have been used as test materials because of their use in the manufacturing sector with high mechanical properties, good corrosion resistance and low thermal conductivity. The effect of feed rate, cutting depth and cooling technique on surface roughness and cutting forces were investigated. In the experiments $0.1,0.2$ and $0.3 \mathrm{~mm} / \mathrm{rev}$ feed rate, $0.5,1$ and $1.5 \mathrm{~mm}$ cutting depth and dry, $\mathrm{MQL}$ and $\mathrm{CO}_{2}$ cooling conditions were used variably. Taguchi technique was used for the experimental design of the turning process. Cutting speed was kept constant. Taguchi technique was used for the experimental design of the turning process. By way of this technique, optimum values were obtained with few experiments. In addition, Grey Relational Analysis (GRA) method was used to determine the optimal parameters level. The optimal GRA value was obtained from experiment number 1 as 0.94 . Accordingly, for the lowest surface roughness and cutting force, the cutting depth and feed rate values should be kept to minimum.
\end{abstract}

Keywords: Grey Relational Analysis, Optimization, AISI 316Ti

\section{GíRiş}

Paslanmaz çelikler, mekanik özelliklerinin yüksek, korozyon direnci iyi olması ve düşük ısıl iletkenlikleri ile imalat sektöründe önemli bir kullanım sahasına sahiptir [1]. Makine ve imalat sanayisinde özellikle östenitik ve ferritik paslanmaz çelikler kullanılmakla beraber yüksek mekanik özellikleri ve eşsiz korozyon direnci sayesinde bu

malzemeler gıdadan sağlığa, kimyadan elektroniğe, savunma sanayinden nükleer santrallere ve otomotivden 
uzay-uçak sanayine kadar, çok geniş alanlarda kullanımları hızlıca yaygınlaşmaktadır [2-4]. Paslanmaz çelikler, düşük 1sıl iletkenlik özellikleriyle şekillendirilmesi yeterince zor malzemeler arasındadır. $\mathrm{Bu}$ özellikler yüksek kesme kuvvetleri, yüksek kesme sıcaklığı, hızlı takım aşınması, zor talaş kırılması, kesici kenara talaş yapışması ve kötü yüzey kalitesine sebep olmaktadır[5].Tornalama işleminde iş parçasının lastik deformasyonu için kullanılan enerji ısıya dönüşmekte olup, bu isının çoğunlukla birinci deformasyon bölgesinde ortaya çıktığı bilinmektedir. Fakat, deformasyon esnasında ortaya çıkan sıcaklık, takım geometrisi ve kesme parametrelerine göre değişen takım-talaş ara yüzeyindeki sürtünme ve kesme kuvvetleriyle yakın bir ilişkisi göstermektedir [6]. Takım-talaş temas uzunluğu, dolayısıyla takım geometrisi, takım ömrü ve işleme verimliliğini doğrudan teması olduğu bilinmektedir [7]. Son dönemlerde, değişik paslanmaz çeliklerden talaş kaldırılması ile oluşan kesme kuvvetleri ve yüzey pürüzlülüğü üzerinde, kesme parametrelerinin etkilerinin incelendiği birçok deneysel çalışmaların yapıldığı görülmektedir. Kaplamalı sementit karbür kesici takımlarla AISI 304 ve AISI 316 paslanmaz çeliklerin işlenebilirliliği araştırılmış ve yüzey pürüzlülüğü $\left(\mathrm{R}_{\mathrm{a}}\right)$ için kesme hızının önem arz eden bir parametre olduğu ortaya konulmuştur [8]. AISI 304 östenitik paslanmaz çeliğin TiC kaplamalı kesici takımla tornalanma işleminde oluşan $F_{c}$ 'nin, teorik ve deneysel sonuçlar arasındaki sapmaların değerlendirilmesi sonucunda, teorik yaklaşımın ortalama \%80 doğrulukla kullanılabileceği vurgulanmıştır [9]. AISI 304 paslanmaz çeliğin tornalanmasında düşük ilerleme ve yüksek kesme hızında, kesme sesi basınç seviyesindeki azalmaya paralel olarak $\mathrm{R}_{\mathrm{a}}$ 'nın ciddi oranda azaldığı gözlenmiştir [10]. Başka bir araştırmada, östenitik paslanmaz çeliğin tornalanmasında yüzey pürüzlülüğü ve kesme kuvveti için optimum kesme parametrelerine göre yapılan doğrulama deneyleri sonucunda, \%23,4'lük bir iyileştirme sağlandığı belirlenmiştir [11]. AISI 304 paslanmaz çeliğinin işlenmesinde oluşan $R_{a}$ için yapılan varyans analizi sonucunda, $\mathrm{R}_{\mathrm{a}}$ üzerinde ilerleme miktarının $\% 51,84$ etkili olduğu gösterilmiştir [12].

İmalat süreclerinin başarılı olabilmesi için sadece üretim zaman1, üretim miktarı ve üretim ekonomisi yeterli olmaz. Bunlarla birlikte önemli olan diğer hususlar ise çevre kirliliğine ve insan sağlığına karşı olan etkisi ile doğrudan ilgili olmalıdır. İnsan sağlığına ve çevre kirliliğine duyarlı farklı soğutma teknikleri kullanılarak yapılan tornalama işlemleri yapılmıştır. $\mathrm{Bu}$ tekniklerin performans karakteristikleri üzerinde alternatif soğutma tekniğinin genel soğutma tekniğine nazaran daha üstün olduğu gözlenmiştir [13-20]. Takım-talaş ve iş parçası-talaş arasındaki uygun değişiklik ve kesme bölgesinde oluşan 1sıdaki azalmaya bağlı olarak takım aşınmasındaki azalma ve yüzey kalitesi iyileşmesi gibi olumlu sonuçları sağlayan MQL tekniğinin bu etkileri önemli sonuçlardır [21]. Aynı zamanda sıvı azot ve karbondioksit de kesme bölgesinin soğutulmasında alternatif soğutma sistemi olarak kullanılmıştır. Sıvı azotlu soğutma sonrası kenar aşınmasının \%55 azaldığ belirtilmiştir [22].

Bu çalışmada; mekanik özelliklerinin yüksek, korozyon direncinin iyi olması ve düşük ssıl iletkenlikleri ile imalat sektöründe önemli bir kullanım sahasına sahip ve literatürde üzerinde az çalışmalar bulunan AISI 316Ti paslanmaz çelik deney malzemesi olarak kullanılmıştır. AISI 316Ti paslanmaz çeliklerin tornalanmasında ilerleme oranı, talaş derinliği ve soğutma sisteminin yüzey pürüzlülüğüne ve kesme kuvvetlerine etkisi araştırıldı. Tornalama işleminin optimizasyonu için Taguchi Gri Analiz tekniği kullanıldı. Bu sayede AISI 316Ti paslanmaz çeliklerin tornalanmasında ilerleme oranı, talaş derinliği ve soğutma sisteminin yüzey pürüzlülügüne ve kesme kuvvetlerine etkisi tayin edildi.

\section{MALZEME VE YÖNTEM}

\subsection{Malzeme}

$130 \mathrm{~mm}$ boyunda ve $60 \mathrm{~mm}$ çapındaki AISI 316Ti malzeme deney malzemesi olarak kullanılmıştır. Malzemenin kimyasal özellikleri Tablo 1'de verilmiştir.

Tablo 1. AISI 316Ti malzemenin kimyasal özellikleri

\begin{tabular}{|l|l|l|l|l|}
\hline $\mathrm{C}$ & $\mathrm{Mn}$ & $\mathrm{P}$ & $\mathrm{S}$ & $\mathrm{Si}$ \\
\hline 0.077 & 2.0 & 0.045 & 0.030 & \multirow{2}{*}{1.0} \\
\cline { 1 - 4 } $\mathrm{Cr}$ & $\mathrm{Ni}$ & $\mathrm{Mo}$ & $\mathrm{Ti}$ & \multirow{2}{*}{} \\
\cline { 1 - 4 } 17.18 & 12.56 & 2.72 & 0.67 & \\
\cline { 1 - 3 } & & \multicolumn{3}{|l|}{} \\
\hline
\end{tabular}

\subsection{Deneysel Düzenek}

Talaş kaldırma işlemi sırasında kesici takım ucu olarak SUMITOMO firmasının üretmiş olduğu CNMG 120408 MM uçlar kullanılmıştır. Deneylerde Johnford TC 35 CNC Fanuc OT X-Z eksenli bir tezgah kullanılmıştır. Deneyde Mahr firmasının perhometer M1 tipi yüzey pürüzlülüğü ölçüm aleti kullanılmıştır. DIN, ISO, JIN, AISI standartlarına göre çeşitli değerlerle yüzey pürüzlülüğü tayin edilir. Bulunan değer ekranda görülmesiyle birlikte $R_{a}, R_{z}$ vb. yüzey pürüzlülük değerlerinde çıktısı bulunabilir. Deneylerde kuvvet ölçümü için KISTLER 9121 kuvvet sensörü, KISTLER 5019b tipi yük amplifikatörü ve DynoWare analiz programı kullanılmıştır (Şekil 1). 


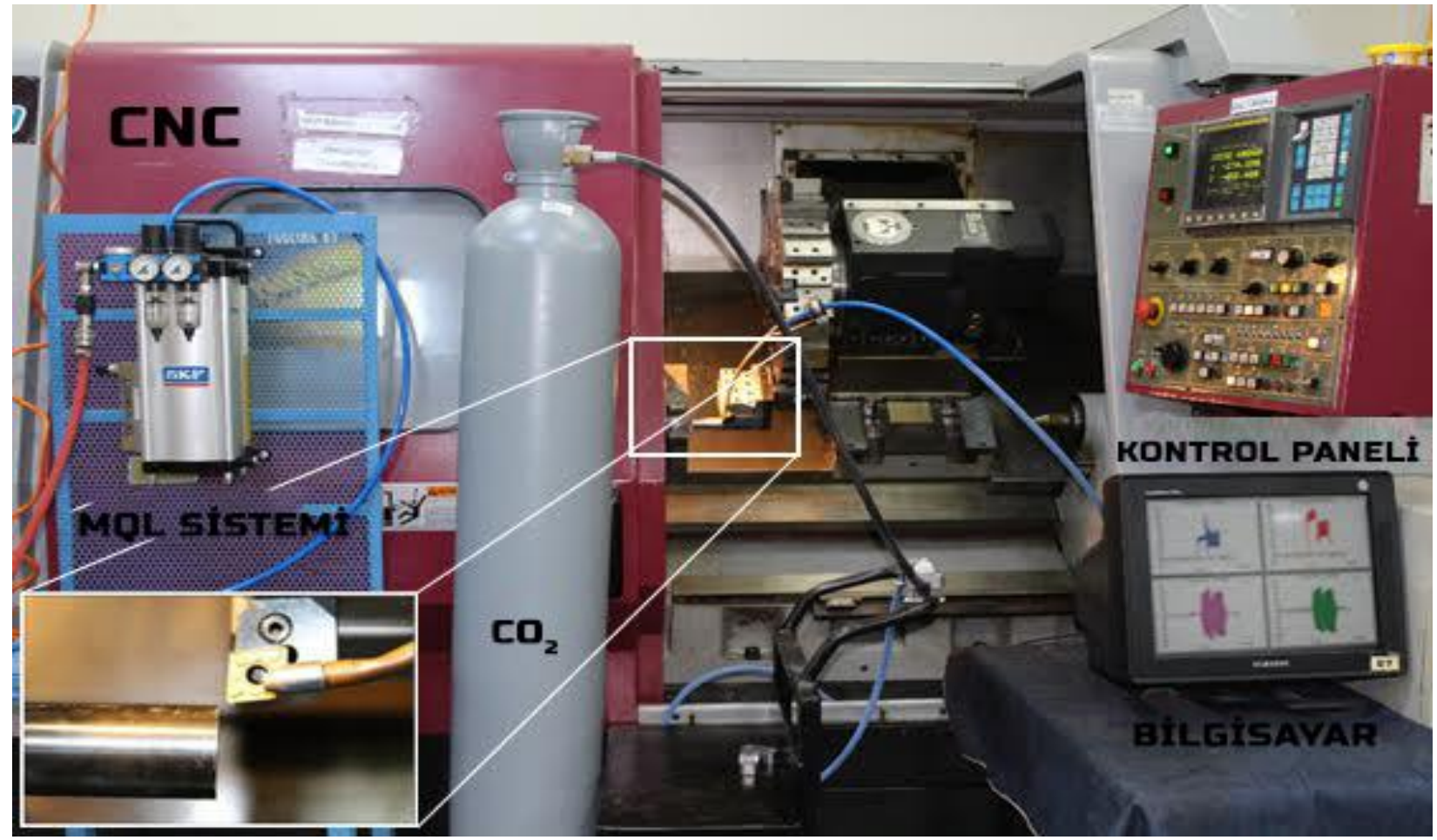

Şekil 1. Deney Düzeneği

İlerleme oranı parametresi için 0.1 ile $0.3 \mathrm{~mm} / \mathrm{dev}$, talaş derinliği için 0,5 ile $1,5 \mathrm{~mm}$ değerleri arasında 3 seviye belirlenmiştir. Soğutma sistemi faktörü için kuru, MQL (Minimum Quantity Librication) ve $\mathrm{CO}_{2}$ seçenekleri incelenmiştir. Tablo 1'de ölçme deneyleri için kesme kuvvetleri ve yüzey pürüzlügüün̈ etkileyen temel faktörler seviyeleri ile birlikte verilmektedir.

Tablo 2. Deney Parametreleri.

\begin{tabular}{|l|c|c|c|}
\hline Parametreler & Seviye 1 & Seviye 2 & Seviye 3 \\
\hline $\begin{array}{l}\text { İlerleme Oranı } \\
(\mathrm{mm} / \mathrm{dev})\end{array}$ & 0,1 & 0,2 & 0,3 \\
\hline $\begin{array}{l}\text { Talaş Derinliği } \\
(\mathrm{mm})\end{array}$ & 0,5 & 1 & 1,5 \\
\hline Soğutma Sistemi & Kuru & MQL & $\mathrm{CO}_{2}$ \\
\hline
\end{tabular}

\subsection{Yöntem}

Deney tasarımı, Taguchi deney tasarım tekniği kullanılarak yapılmıştır. Böylece, daha az deney ile daha geniş kapsamlı sonuçlara ulaşmak mümkün olmuştur. Bu durumda, zaman ve maliyetten kazanım sağlanmıştır. Kalite karakteristiğini belirlerken, ölçülecek yüzey pürüzlülüğü ve kesme kuvveti oranlarının en az olması istendiğinden dolayı, deneyler sonucunda ulaşılması beklenen kalite değerlerinden, en küçük en iyidir prensibi uygulanmıştır [23]. Taguchi L9 ortagonal dizisine göre gerçekleştirilen deneyler parametrelere ait seviyeler Tablo 3'de verilmiştir.

Tablo 3. Taguchi L L $_{9}$ Deney Tasarımı ve Deney Sonuçları.

\begin{tabular}{|c|c|c|c|c|c|}
\hline \multirow{2}{*}{$\begin{array}{c}\text { Den } \\
\text { ey } \\
\text { no. }\end{array}$} & \multicolumn{3}{|c|}{ Kontrol Seviyeleri } & \multirow[b]{2}{*}{$\begin{array}{c}\text { Kesm } \\
\text { e } \\
\text { Kuvv } \\
\text { eti } \\
\text { (N) }\end{array}$} & \multirow{2}{*}{$\begin{array}{c}\text { Yüzey } \\
\text { Pürüzzlül } \\
\text { ğü } \\
\mathbf{R}_{\mathbf{a}}(\boldsymbol{\mu m})\end{array}$} \\
\hline & $\begin{array}{c}\text { İlerlem } \\
\text { e Oranı } \\
(\mathrm{mm} / \mathrm{de} \\
\mathrm{v})\end{array}$ & $\begin{array}{c}\text { Talaş } \\
\text { Derinli } \\
\text { ği } \\
(\mathrm{mm})\end{array}$ & $\begin{array}{c}\text { Soğut } \\
\text { ma } \\
\text { Sistem } \\
\text { i }\end{array}$ & & \\
\hline 1 & 1 & 1 & 1 & $\begin{array}{c}127,8 \\
61\end{array}$ & 0,618 \\
\hline 2 & 1 & 2 & 2 & $\begin{array}{c}235,3 \\
89\end{array}$ & 0,406 \\
\hline 3 & 1 & 3 & 3 & $\begin{array}{c}394,3 \\
56\end{array}$ & 0,641 \\
\hline 4 & 2 & 1 & 2 & $\begin{array}{c}213,4 \\
03\end{array}$ & 1,519 \\
\hline 5 & 2 & 2 & 3 & $\begin{array}{c}680,9 \\
35\end{array}$ & 1,493 \\
\hline 6 & 2 & 3 & 1 & $\begin{array}{c}559,5 \\
72\end{array}$ & 1,449 \\
\hline 7 & 3 & 1 & 3 & $\begin{array}{c}301,6 \\
59\end{array}$ & 3,457 \\
\hline 8 & 3 & 2 & 1 & $\begin{array}{c}523,6 \\
54\end{array}$ & 3,694 \\
\hline 9 & 3 & 3 & 2 & $\begin{array}{c}708,5 \\
67\end{array}$ & 3,380 \\
\hline
\end{tabular}




\subsection{Gri İlişki Analizi (GRA)}

Gri ilişkisel Analizinde; siyah, bilgiye sahip olmadığını, beyaz, bilgiye tamamen sahip olduğunu gösterir. Gri sistem ise, siyah ile beyaz arasındaki bilginin seviyesini gösterir. Diğer bir ifadeyle gri sistemde bazı bilgiler bilinmekle beraber bazı bilgiler bilinemez. Beyaz sistemde, sistem içerisindeki ilişkiler arası faktörler kesindir. Gri sistemde ise sistem içerisindeki ilişkiler arası faktörler kesin değildir [2528]. Gri iliş̧kisel analiz (GRA) gri modellemenin alt başlıklarından biridir. GRA gri bir sistemdeki her bir faktör ile kıyas yapılan faktör serisi arasındaki ilişki derecesini belirlemeye yarayan bir yöntemdir. Her bir faktör bir dizi olarak tanımlanır. Faktörler arası etki derecesi ise gri ilişkisel derece olarak isimlendirilir [25-28].

Gri ilişkisel analiz metodunun hesaplama adımları aşağıdaki gibidir [25-28]:

1. Adım: $\mathrm{n}$ uzunluğundaki referans seri aşağıdaki gibi olsun; (Eşitlik 1).

$$
x_{0}=\left(x_{0}(1), x_{0}(2), x_{0}(3), \ldots, x_{0}(n)\right)
$$

\section{Adım: Verilerin normalize edilmesi;}

Faktörlerin farklı kaynaklardan geldiği, farklı birimlerde ölçüldüğü düşünüldüğünde GA'nın ilk adımı verilerin aynı birime dönüștürülmesidir. Ayrıca serinin çok geniş aralıklarda değerler aldığı durumlarda standartlaştırmayla verilerin küçük bir aralığa çekilmesinde de fayda vardır. Gri sistem teorisinde bu normalleştirme projesine "gri ilişkisel oluşum (grey relational generating)" adı verilmektedir. Verilerin normalizasyonunda en sık kullanılan yöntemlerden birisi lineer veri önişleme metodudur. Faktör serilerinin normalizasyonunda dikkat edilmesi gereken " daha yüksek daha iyi", "daha düşük daha iyi" ve "en ideal en iyi" kriterlerinden hangisinin serinin özelliğini yansıtır. Örneğin serideki noktaların küçük değerler olması istenen bir özellik ise lineer normalizasyonda küçük değer alan noktalar normalizasyonda " 1 " e yakın değerler alırken, büyük değer alan noktalar " 0 " 'a yakın değerler alacaktır.

"Daha yüksek daha iyi" durumunda normalizasyon Eşitlik 2'deki gibidir.

$$
x_{i}(k)=\frac{x_{i}^{0}(k)-\min x_{i}^{0}(k)}{\max x_{i}^{0}(k)-\min x_{i}^{0}(k)}
$$

$\mathrm{x}_{i}(\mathrm{k})$, i serisi $\mathrm{k}$. sıradaki orjinal değer, $\mathrm{x}_{i}(\mathrm{k})$ normalizasyon sonrası i. seri k. sırasındaki değer, $\min \mathrm{x}_{0}(\mathrm{k})$ serisindeki minimum değer, $\max x_{i}(k)$ i serisindeki maksimum değerdir.

“Daha düşük daha iyi” için Eşitlik 3'deki gibidir; $x_{i}(k)=\frac{\max x_{i}^{0}(k)-x_{i}^{0}(k)}{\max x_{i}^{0}(k)-\min x_{i}^{0}(k)}$

"İdeal değer daha iyi” için Eşitlik 4’deki gibidir;

$$
x_{i}(k)=1-\frac{\left|x_{i}^{0}(k)-x^{0}\right|}{\max x_{i}^{0}(k)-x^{0}}
$$

Burada $\mathrm{x}^{0}$ istenilen ideal değeri göstermektedir.

3. Adım: $x_{0}$ serisi ile karşılaştırılacak $m$ tane seri Eşitlik 5 'te tanımlanmış olsun.

$$
x_{i}=\left(x_{i}(1), x_{i}(2), x_{i}(3), \ldots, x_{i}(n)\right) \quad \mathrm{i}=1,2, \ldots, \mathrm{m}
$$

4. Adım: $\mathrm{k}, \mathrm{n}$ uzunluğundaki serideki k. Sırayı göstersin $\varepsilon$ $\left(\mathrm{x}_{0}(\mathrm{k}), \mathrm{x}_{\mathrm{i}}(\mathrm{k})\right)$, $\mathrm{k}$. noktadaki gri ilişkisel katsayı olup eşitlik $6,7,8$ ve 9'a göre hesaplanır.

$$
\varepsilon\left(x_{0}(k), x_{i}(k)\right)=\frac{\Delta_{\min }+\xi \Delta_{\min }}{\Delta_{0 \mathrm{i}}(k)+\xi \Delta_{\max }}
$$

$$
\Delta_{0 i}(k)=\left|x_{0}(k)-x_{j}(k)\right|
$$

$$
\Delta_{\text {min }}=\min _{j} \min _{k}\left|x_{0}(k)-x_{j}(k)\right|
$$

$$
\Delta_{\max }=\max _{j} \max _{k}\left|x_{0}(k)-x_{j}(k)\right|
$$

Ve $\xi \in(0,1)$ arasındaki bir katsayıdır. j=1,2,..m; $\mathrm{k}=1,2, \ldots, \mathrm{n}$. $\xi$ ışlevi, $\Delta_{0 i}$ ile $\Delta_{\max }$ arasındaki farkı ayarlamaktır. Çalışmalar $\xi$ değerinin gri ilişkisel derece sonrası oluşacak sıralamayı etkilemediğini göstermektedir.

5. Adım: Son olarak gri ilişkisel derece ise eşitlik 10 ile hesaplanır;

$\gamma\left(x_{0}, x_{i}\right)=\frac{1}{n} \sum_{k=1}^{n} \varepsilon\left(x_{0}(k), x_{i}(k)\right)$

$\gamma\left(x_{0}, x_{i}\right)$ gri bir sistemdeki $x_{i}$ serisi ile $x_{0}$ referans serisi sırasındaki geometrik benzerliği n bir ölçüsüdür. Gri ilişkisel derecesinin büyüklüğü $x_{i}$ ile $x_{0}$ arasında kuvvetli bir ilişki olduğunu $\mathrm{n}$ göstergesidir. Eğer karşılaştırılan iki seri birbirinin aynı ise gri ilişkisel derece değeri 1 olarak bulunur. 
Gri ilişkisel derece karşılaştırılan serinin referans seriye ne kadar benzer olduğunu gösterir.

Eğer her bir kriterin ağırlıkları verildiyse, kriterin gri ilişki katsayısı ile kriterin önem derecesine ilişkin ağırlık değeri çarpılarak gri ilişki derecesi bulunabilir. Bu Eşitlik 11'e göre hesaplanır.

$\gamma\left(x_{0}, x_{i}\right)=\frac{1}{n} \sum_{k=1}^{n} \varepsilon\left(x_{0}(k), x_{i}(k) .\left(\mathrm{W}_{i}(\mathrm{k})\right)\right)$

Karar verme probleminde referans seri, kriterlerin almas1 istenen en büyük, en küçük ve en ideal değerler olarak seçilirse, karşılaştırması yapılacak faktör serinin referans seriye göre hesaplanacak gri ilişkisel derecesi kriterleri yakalama seviyesinin bir göstergesi olacaktır. Diğer bir deyişle gri ilişkisel derecesi en yüksek olan faktör serisi (alternatif) karar verme probleminde en iyi karar verme alternatifini gösterecektir [25-28].

\section{BULGULAR}

\subsection{Gri İlișki Analiz Yöntemiyle Parametrelerin Optimizasyonu}

Kesme kuvvetleri ile yüzey pürüzlüğü sonuçları arasında Gri ilişki analizi yapıldıktan sonra elde edilen GRA değerleri Tablo 4'de verilmiştir. Buna göre en ideal değer 1 numaralı GRA Rank değeri ile gösterilen 1'nolu deneyle gerçekleşirken, en kötü sonuç 9 numaralı deneyle elde edilmiştir.

Tablo 4. Gri İlişkisel Analizi.

\begin{tabular}{|c|c|c|c|c|c|c|}
\hline \multirow{2}{*}{$\begin{array}{c}\text { Deney } \\
\text { No }\end{array}$} & \multicolumn{2}{|c|}{ Normalizasyon Değerleri } & \multicolumn{2}{c|}{ Toplam Değerler } & \multicolumn{2}{c|}{ Gri ilişkisel derece } \\
\cline { 2 - 6 } & $\begin{array}{c}\text { Kesme } \\
\text { Kuvveti }\end{array}$ & $\begin{array}{c}\text { Yüzey } \\
\text { Pürüzlülüğü }\end{array}$ & $\begin{array}{c}\text { Kesme } \\
\text { Kuvveti }\end{array}$ & $\begin{array}{c}\text { Yüzey } \\
\text { Pürüzlülü̆ğü }\end{array}$ & $\begin{array}{c}\text { GRA } \\
\text { Değerleri }\end{array}$ & GRA Rank \\
\hline 1 & 1,000 & 0,988 & 0,000 & 0,062 & 0,994 & 1 \\
\hline 2 & 0,964 & 1,000 & 0,185 & 0,000 & 0,982 & 2 \\
\hline 3 & 0,916 & 0,986 & 0,459 & 0,069 & 0,951 & 4 \\
\hline 4 & 0,971 & 0,937 & 0,147 & 0,336 & 0,954 & 3 \\
\hline 5 & 0,840 & 0,938 & 0,952 & 0,329 & 0,889 & 6 \\
\hline 6 & 0,871 & 0,941 & 0,743 & 0,315 & 0,906 & 5 \\
\hline 7 & 0,944 & 0,843 & 0,299 & 0,928 & 0,894 & 7 \\
\hline 8 & 0,880 & 0,833 & 0,682 & 1,000 & 0,857 & 8 \\
\hline 9 & 0,833 & 0,847 & 1,000 & 0,904 & 0,840 & 9 \\
\hline
\end{tabular}

Şekil 2'de deney numaraları ve deneylere karşılık gelen Gri ilişkisel analiz değerleri çizgi grafiği şeklinde görülmektedir.
Buna göre en iyi sonuç 1 numaralı deneyde elde edilirken en kötü sonuç 9 numaralı deneyde ortaya çıkmıştır.

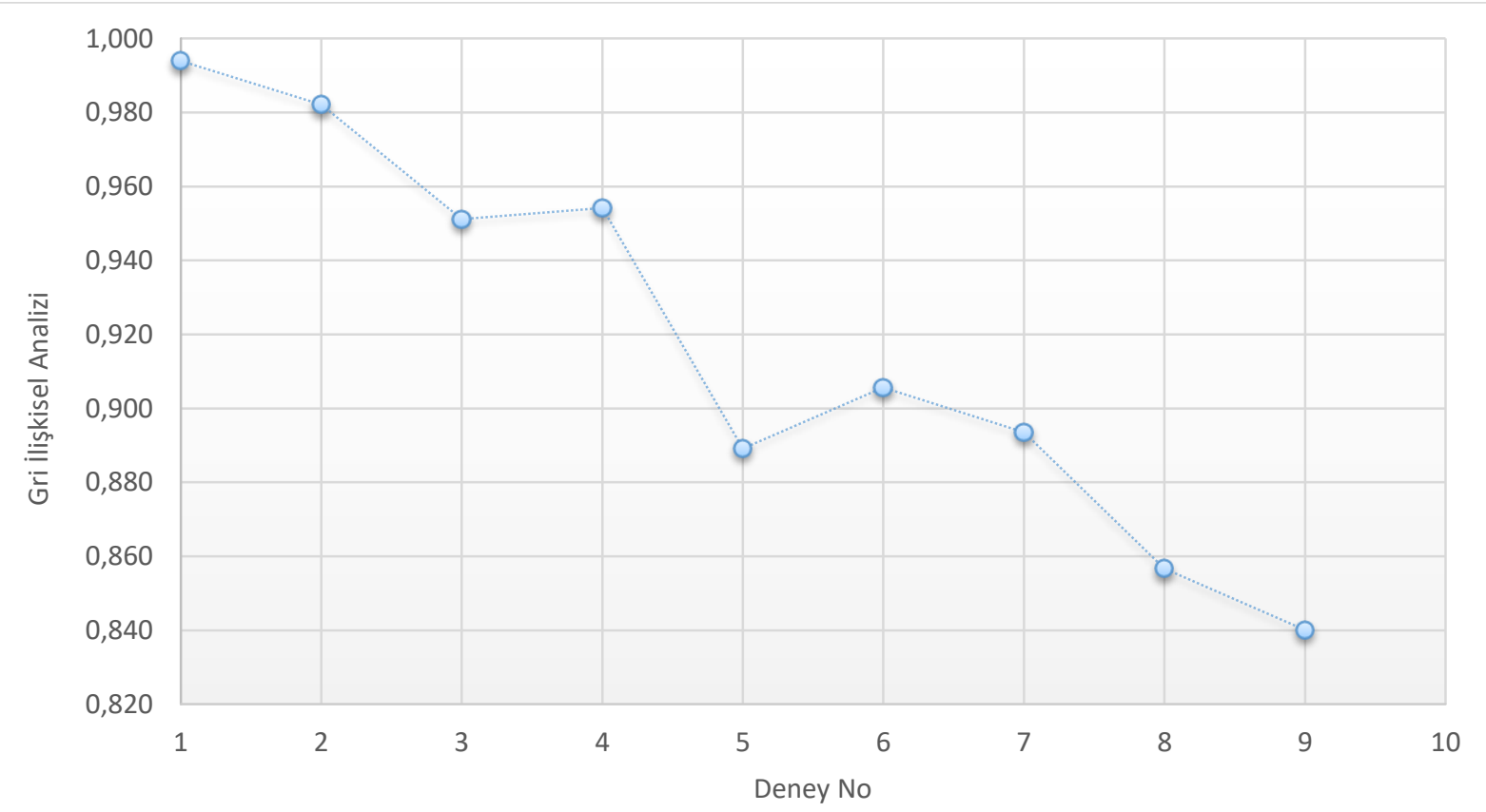

Şekil 2. Deneyler için gri ilişkisel analiz grafiği 


\section{SONUÇ VE TARTIȘMA}

Bu çalışmada; savunma, havacılık sanayii gibi alanlarda yaygın olarak kullanılan AISI 316Ti paslanmaz çelik malzemenin $\mathrm{CNC}$ torna tezgâhında işlenmesi sırasında meydana gelen kesme kuvvetleri ve yüzey pürüzlüğü değerleri ölçülmüş ve bu değerleri etkileyen temel parametreler etki değerleri ile birlikte istatistiksel metotlar kullanılarak belirlenmiştir.

Öncelikle Taguchi tasarım metodu kullanılarak yapılması gereken ölçüm sayısı ve parametre değerleri belirlenmiştir. Ardından yüzey pürüzlüğü ve kesme kuvvetleri ölçümlerinden sonra en iyi parametre seviyelerinin belirlenmesi için Gri İlişki analizi metodu kullanılmış ve en ideal değerlerin 1 nolu deneyle elde edildiği görülmüsstür. Buna göre en düşük yüzey pürüzlüğü için talaş derinliğinin ve ilerleme oranı değerlerinin minimum tutulması gerekmektedir. GRA değeri 0,994 olarak 1'nolu deneyden elde edilmiştir. Fakat yapılan deneylerin sonuçları incelendiğinde ilerleme oranın $0.5 \mathrm{~mm} / \mathrm{dev}$, talaş derinliğinin $1 \mathrm{~mm}$ ve soğutma sisteminin $\mathrm{MQL}$ olduğu

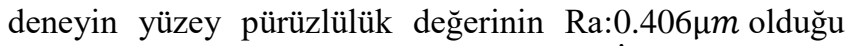
görülmektedir. Talaş derinliğinin de Gri İlişki analizinde optime edilen 1 numaralı deneydeki talaş derinliğinin iki katı olması da kesme kuvveti değerinin iki deneyde de yakın değerlere karşılık geldiği hatta iki numaralı deneyin kesme kuvveti değeri ilk deneyden daha düşüktür. Buradan da MQL soğutma sisteminin hem yüzey pürüzlülüğüne hem de kesme kuvvetine olumlu etki ettiği anlaşılmıştır. Çıkan sonuçlar literatürle de örtüşmektedir [21, 24-26, 28].

Sonuç olarak;

- Yüzey pürüzlülüğüne ilerleme oranının ve MQL soğutma sisteminin etkili olduğu,

- Kesme kuvvetine talaş derinliğinin etkin parametre olduğu anlaşılmıştır.

\section{KAYNAKÇA}

[1] Kosa,T., Ronald, P., "Machining of stainless steels", Handbook: Machining, Vol. 16, 9th Edition, Editor: J. R. Davis, Metals Park, Ohio, 1989.

[2] M'Saoubi, R., Outeiro, J.C., Changeux, B., Lebrun, J.L., Dias, A.M., "Residual stress analysis in orthogonal machining of standard and resulfurized AISI 316L steels", Journal of Materials Processing Technology, vol.96, pp. 225233, 1999.

[3] Darwin, J.D., Lal, D.M., Nagarajan, G., "Optimization of cryogenic treatment to maximize the wear resistance of $18 \% \mathrm{Cr}$ martensitic stainless steel", Journal of Materials Processing Technology, vol.195, pp. 241-247, 2008.

[4] Outeiro, J.C., Umbrello, D., M'Saoubi, R., "Experimental and numerical modelling of the residual stresses induced in orthogonal cutting of AISI 316L steel", International Journal of Machine Tools and Manufacture, vol.46, pp. 1786-1794, 2006.

[5] Agrawal, B.K., Introduction to Engineering Materials, Mc Graw-Hill Publishing Co., New Delhi, 1983.
[6] Maranhao, C., Davim, J.P., "Finite element modelling of machining of AISI 316 steel: Numerical simulation and experimental validation", Simulation Modelling Practice and Theory, vol.18, pp. 139-156, 2010.

[7] Korkut, I., Boy, M., Karacan, I., Seker, U., "Investigation of Chip-back temperature during machining depending on cutting parameters", Materials and Design, vol.28, pp. 23292335, 2007.

[8] Ciftci, İ., "Machining of austenitic stainless steels using CVD multi-layer coated cemented carbide tools", Tribology International, vol.39, pp. 565-569, 2006.

[9] Tekaslan, Ö., Gerger, N., Günay, M., Şeker, U., “AISI 304 östenitik paslanmaz çeliklerin titanyum karbür kaplamalı kesici takım ile tornalama işleminde kesme kuvvetlerinin incelenmesi”, Pamukkale Üniversitesi Mühendislik Bilimleri Dergisi, vol.13, pp. 129-286, 2007.

[10] Tekiner, Z., Yeşilyurt, S., 'Investigation of the cutting parameters depending on process sound during turning of AISI 304 austenitic stainless steel", Materials and Design, vol. 25, pp. 507-513, 2004.

[11] Li, S., Liu, Y., Zhu, R., Li, H., Ding, W., "Study on turning parameter optimization of austenitic stainless steel", Applied Mechanics and Materials, 34-35, pp. 1829-1833, 2010.

[12] Selvaraj, D.P., Chandramohan, P., "Optimization of surface roughness of AISI 304 austenitic stainless steel in dry turning operation using Taguchi design method", Journal of Engineering Science and Technology, vol.5 (3), pp. 293-301, 2010.

[13] Diniz, A.E., Ferreira, J.R., Filho, F.T., "Influence of refrigeration/lubrication condition on SAE 52100 hardened steel turning at several cutting speeds", International Journal of Machine Tools and Manufacture, vol.43, pp. 317-326, 2003.

[14] Kishawy, H.A., Dumitrescu, M., Ng, E.G., Elbestawi, M.A., "Effect of coolant strategy on tool performance, chip morphology and surface quality during highspeed machining of A356 aluminum alloy", International Journal of Machine Tools and Manufacture, vol.45, pp. 219-227, 2005.

[15] Dhar, N.R., Kamruzzaman, M., Ahmed, M., "Effect of minimum quantity lubrication (MQL) on tool wear and surface roughness in turning AISI-4340 steel", Journal of Materials Processing Technology, vol.172, pp. 299-304, 2006.

[16] Itoigawa, F., Childs, T.H.C., Nakamura, T., Belluco, W., "Effects and mechanisms in minimal quantity lubrication machining of an aluminum alloy", Wear, vol.260, pp.339-344, 2006.

[17] Dhar, N.R., Islam, M.W., Islam, S., Mithu, M.A.H., "The influence of minimum quantity of lubrication (MQL) on cutting temperature, chip and dimensional accuracy in turning AISI-1040 steel", Journal of Materials Processing Technology, vol.171, pp. 93-99, 2007.

[18] Ezugwu, E.O., Bonney, J., Da Silva, R.B., Çakır, O., "Surface integrity of finished turned Ti-6Al-4V alloy with PCD tools using conventional and high pressure coolant supplies", International Journal of Machine Tools \& Manufacture, vol.47, pp.884-891, 2007. 
[19] Attanasio, A., Gelfi, M., Giardini, C., Remino, C., "Minimal quantity lubrication in turning: Effect on tool wear", Wear, vol.260, pp. 333-338, 2006.

[20] Bruni, C., Forcellese, A., Gabrielli, F., Simoncini, M., "Effect of the lubrication-cooling technique, insert technology and machine bed material on the workpart surface finish and tool wear in finish turning of AISI 420B", International Journal of Machine Tools and Manufacture, vol.46, pp.1547-1554, 2006.

[21] Liu, J., Han, R., Sun, Y., "Research on experiments and action mechanism with water vapor as coolant and lubricant in Green cutting", International Journal of Machine Tools \& Manufacture, vol.45, 687-694, 2005.

[22]M. Stanforda, P.M. Listerb, , C. Morgana, , K.A. Kibblea, "Investigation into the use of gaseous and liquid nitrogen as a cutting fluid when turning BS 970-80A15 (En32b) plain carbon steel using WC-Co uncoated tooling",Journal of Materials Processing Technology, vol. 209, Issue 2, pp. 961-972, 19 January 2009.
[23] Phillip J. Ross, Taguchi Techniques for Quality Engineering, 1996.

[24] G. Basmac1, "Tornalamada Minimum Miktarda Yağlama (MQL) Tekniğinin Takım Ve Iş Parçası Üzerine Etkilerinin İncelenmesi”, Doktora Tezi, Marmara Üniversitesi Fen Bilimleri Enstitüsü, İstanbul, 2012.

[25] M. Ay, Acta Physica Polonica A, 131(3), 349-353, (2017), Doi: 10,12693/ APhysPolA. 131349.

[26] G. Basmac1, M. Ay, Acta Physica Polonica A, 131(3), 354-358, (2017). Doi: 10.12693/APhysPolA.131.354.

[27] M. Ay, Y. Altunpak, S. Hartomacıoğlu, Acta Physica Polonica A, 131(3), 551-554, (2017). Doi: 10.12693/APhysPolA.131.551

[28] G. Basmacı, M. Ay, İ. Kırbaş, "Optimisation of Machining Parameters in Turning 17-4 Ph Stainless Steel Using the Grey-Based Taguchi Method", Erzincan University Journal of Science and Technology, vol.10-2, pp. 243-254, 2017. 